\title{
Filosofía y Literatura: El rol de la distinción phýsis y tékhne en la construcción de los géneros literarios
}

\author{
MARIANA CASTILLO MERLO \\ IPEHCS-CONICET \\ Universidad Nacional del Comahue
}

DOI: $10.36446 /$ rlf2021193

Resumen: En ¿Qué es un género literario? (1989), J.-M. Schaeffer acusa a Aristóteles de una ambigüedad inicial que habría condicionado el análisis de los géneros literarios a lo largo de su historia. Teniendo en cuenta algunas lecturas "literarias" y "filosóficas" de Poética, en este trabajo pretendo analizar las perspectivas naturalista-esencialista, histórica-analítica y normativa desde las cuales Aristóteles lleva adelante su empresa. En tal sentido, evaluaré, por un lado, los alcances de dichas perspectivas en dos momentos particulares de la Poética (1447a-1448b y 1448b-1449a) y, por otro, la manera en que cada una de ellas pone en juego la distinción aristotélica entre phýsis y tékhne.

Palabras clave: Poética, género literario, enfoque interdisciplinar, dificultades hermenéuticas. 


\title{
Philosophy and Literature: The Role of the Distinction between Phýsis and Tékhne in the Construction of Literary Genres
}

\begin{abstract}
In What is a literary genre? (1989), J.-M. Schaeffer accuses Aristotle of an initial ambiguity that would have conditioned the analysis of literary genres throughout its history. Taking into account some "literary" and "philosophical" readings of Poetics, in this paper I intend to point out the naturalistic-essentialist, historical-analytical and normative perspectives from which Aristotle carries out his project. For that purpose, I will evaluate, on the one hand, the scope of these perspectives in two particular moments of the Poetics (1447a-1448b and 1448b-1449a) and, on the other hand, the way in which each of them involve the Aristotelian distinction between phýsis and tékhne.
\end{abstract}

Key-words: Poetics, literary genres, interdisciplinary approach, hermeneutical problems.

\section{Introducciön}

Tay un supuesto bastante difundido y aceptado por quienes se 1 dedican a la teoría de los géneros literarios que asume que "la historia de la teoría genérica no es otra cosa que la historia del aristotelismo en la teoría de la literatura" (Willems 1981:244). En parte, es posible afirmar que dicho supuesto es cierto y que el carácter veritativo-funcional de dicho enunciado se debe al efecto e influjo que la teoría aristotélica efectivamente desempeñó en los estudios literarios a lo largo de su historia. El problema es que dicho supuesto parecería otorgarle a la teoría poética aristotélica una unidad de la que carece y soslaya la multiplicidad de dificultades léxicas y hermenéuticas que se suscitan ni bien comienza el texto.

La empresa que Aristóteles emprende en la Poética ${ }^{1}$ lejos está de ofrecer una solución unívoca al fenómeno poético, en general, y al trágico, en particular. En ¿Qué es un género literario? (1989), el filósofo Jean-Marie Schaeffer acusa a Aristóteles de una ambigüedad inicial que habría condi-

\footnotetext{
${ }^{1}$ Sigo la traducción española de García Yebra 1974 por considerarla un referente para los lectores de habla hispana. Sin embargo, en algunos casos he modificado la traducción y aclarado entre corchetes el sentido que, a mi entender, tienen algunas expresiones. En todos los casos, se indican dichas modificaciones al texto.
} 
cionado el análisis de los géneros literarios. Luego de reconocer la importancia del análisis realizado por el Estagirita, señala dos movimientos que ponen en tensión la dupla phýsis-tékhne. Por un lado, Aristóteles sería el primer autor en abordar de manera sistemática la poesía bajo un ángulo genérico, el primero en sostener explícitamente que la definición del arte poético halla su prolongación natural en el análisis de su constitución genérica. Por otro, en el modo de clasificar los géneros, Aristóteles le adjudicaría a la poesía una naturaleza propia y, quizás por ello mismo, asume que el ámbito literario, a pesar de ser una creación, se organiza según un orden natural. Sin embargo, la mirada naturalista no es el único prisma desde el cual analizar la poesía y en la Poética se pondrían en juego, al menos, otras dos perspectivas que acentúan su carácter artificial.

En este trabajo, pretendo analizar las distintas perspectivas desde las cuales Aristóteles lleva adelante su empresa y enfatizar las conexiones que se establecen entre lo que Schaeffer denomina una visión naturalista-esencialista, una histórica-analítica y una normativa del género trágico. A partir de ello, evaluaré, por un lado, los alcances de cada una de estas perspectivas en dos momentos particulares de la Poética (1447a-1448b y 1448b-1449a) y, por otro, la manera en que cada una de ellas pone en juego la distinción aristotélica entre phýsis y tékhne.

\section{De perspectivas e interpretaciones o sobre la Poética y su historia}

A ntes de comenzar con el análisis de la Poética considero necesario Arealizar una serie de advertencias que permitan comprender algunas de sus particularidades. La Poética es, probablemente, uno de los textos aristotélicos más comentados y el que más repercusiones ha tenido en la historia de la cultura occidental. Pese a esta importancia, y a los innumerables trabajos destinados a dicha obra, algunos de sus conceptos más relevantes siguen generando controversias entre los distintos intérpretes. Diversos argumentos podrían justificar la situación: los avances en el ámbito de la filología, los cambios de intereses desde los cuales se interpreta la obra, la revisión de los usos, sentidos y lecturas que recibió a lo largo de su historia, etc. También es un texto que ha sido interpretado desde perspectivas diferentes, atendiendo a cuál sea el ámbito del que proviene quien la estudia. Halliwell señala, a mi entender con acierto, la existencia de dos grupos en el abordaje de dicha obra; a saber: [1] aquellos que lo hacen desde la crítica literaria y [2] aquellos que lo hacen desde la filosofía. Ambas perspectivas resultan ser, sin embargo, insatisfactorias. Mientras los primeros muestran un mayor interés 
por la obra en sí misma, pero la desligan del resto del corpus aristotélico, los segundos relegan las temáticas abordadas en la Poética por considerar que se trata de temas tangenciales a la "verdadera" filosofia aristotélica (véase Halliwell 1998: 2-3). ${ }^{2}$

Quienes se ocupan de la Poética desde el campo de estudio de la literatura [1] -y asumen una lectura "literaria" de la obra- coinciden en reconocer en ella la piedra de toque fundamental. El texto parece haber permanecido en estado letárgico durante más de mil años hasta convertirse, a partir del siglo XV, en "el más influyente de todos estos libros [de crítica literaria]" (Long 1990: 579), en "la obra básica en el pensamiento literario europeo" (Bobes, Bahamonde, Cueto et al. 1995: 87), en "la piedra angular de los estudios literarios en el dominio cultural occidental” (Dolězel [1990] 1997: 31), en "la primera gran Teoría de los géneros literarios, hasta tal punto que se podría decir que la historia de la teoría genérica occidental no es, en lo sustancial, más que una vasta paráfrasis de ella” (Garrido Gallardo 1988: 9).

Desde esta perspectiva, mientras declinaba, a partir del siglo XIII, el influjo del pensamiento aristotélico en el ámbito de las ciencias y de la propia filosofia, por ser identificado con las posiciones más conservadoras, crecía de manera inversamente proporcional su admiración en los círculos literarios. Dicha fascinación por el texto y su impronta en este ámbito explicaría, al menos en parte, que el concepto mismo de poética se utilice como sinónimo de teoría de la literatura. En este sentido, y asumiendo un lugar

${ }^{2}$ Agradezco a los/las evaluadores/as del artículo por sus comentarios sobre esta sección. En tal sentido, aclaro que asumo como propia la apreciación que hiciera Lacoue-Labarthe acerca del rol que desempeñó la determinación aristotélica de la relación entre arte y naturaleza, al punto de considerarla como "lugar de un esquema matricial y el índice de una coerción histórico-teórica" (2010: 24). Si aceptamos esa caracterización como la premisa que alienta este trabajo, se entenderá por qué surge la necesidad de cuestionar aquello que se ha naturalizado como interpretación en el ámbito de la crítica literaria y la filosofía, como los ámbitos en los que más repercusiones ha tenido el texto aristotélico. Analizar y ejemplificar, aunque sea sucintamente (como es el caso aquí), de qué manera se han constituido ciertos cánones, su interacción y dinámica, es una forma de alentar dicho cuestionamiento. Halliwell, en un sentido similar, justifica el interés de revisar la poética griega por "el hecho de que esas ideas formen parte de la genealogía de argumentos y actitudes en cuyas formas modernas aún pueden estar investidos algunos de nuestros valores" (Halliwell, 2011: 5). Asimismo, y pese a dedicarme hace años al estudio "filosófico" de la Poética, considero que dar cuenta de un abordaje "integral" de la obra es una tarea hermenéuticamente imposible. En este sentido, hago también propia la consideración de $\varnothing$. Andersen y J. Haarberg, quienes, en el intento por "dar sentido" a la Poética, advierten que "la historia de la recepción de la Poética en Occidente es tan abrumadora como compleja, lo que quizás explique por qué nadie se ha atrevido a dar una explicación completa de ella" (2003: 1, énfasis propio). 
común, Todorov reconoce, al igual que lo hace Schaeffer, que "Aristóteles dejó el primer tratado sistemático y ningún otro texto podrá compararse, por su importancia histórica, con su Poética: en cierto modo, toda la historia de la poética no es sino la reinterpretación del texto aristotélico" (Ducrot y Todorov [1972] 1991: 100).

Por su parte, la lectura "filosófica" de la Poética $[2]^{3}$ tiene como característica principal ubicar al pequeño tratado en un lugar muy próximo a la Retórica. Los argumentos para dicho acercamiento se centran, en su gran mayoría, en la división de las ciencias propuesta por el propio Estagirita. En tal sentido, ambas obras se enmarcan dentro de las disciplinas productivas (poietikés) y constituyen, junto a otros escritos actualmente perdidos, tales como Sobre los Poetas, el Grilo y Problemas Homéricos, la principal contribución aristotélica a la teoría del arte (tékhne).

Dicha ubicación de la Poética sigue, al mismo tiempo, la división de las obras aristotélicas en escritos exotéricos y esotéricos. Según esta clasificación, producto del análisis filológico y centrada en la cronología y el carácter de los escritos, existe una fuerte división entre las obras perdidas y las obras conservadas, entre los escritos de juventud y los de madurez del Estagirita. Los primeros, de los que actualmente solo se conservan algunos fragmentos, estaban escritos en su mayoría en forma de diálogo y revisados para su edición. La Poética, en cambio, se ubica dentro de la categoría de obra acroamática, esto es, dentro de los textos de Aristóteles destinados a una ampliación oral, lo cual se funda no solo en el carácter del texto, sino también en lo afirmado por el propio Aristóteles en Poética 1454b18, en donde contrapone explícitamente la Poética con los ekdedoménoi lógoi, esto es, con los textos publicados.

Reconocidos intérpretes del pensamiento aristotélico se hacen eco de dicha división, entre ellos Ross (1923), Brun (1961), Moreau (1962), Düring (1966), Lloyd (1968) y Barnes (1982), ${ }^{4}$ y coinciden en dedicarles un capítulo especial a la Poética junto a la Retórica, bajo la rúbrica de "crítica literaria", "teoría de la creación", "las artes" o, directamente, "Retórica y Poética".

\footnotetext{
${ }^{3}$ Sobre los distintos "paradigmas interpretativos" de la Poética, véase la sucinta presentación al dossier, publicado en Les etudes philosophiques, dedicado a "La poétique d'Aristote: lectures morales et politiques de la tragédie" (Destrée 2003: 433-434).

${ }^{4}$ La selección de estos autores, además de ilustrativa, pretende mostrar cómo aparece la Poética en el relato de la historia de la filosofía antigua y del aristotelismo, a través de obras generales y de referencia. Se trata de retomar la pregunta siempre inquietante, y pocas veces explícita, acerca de los puntos de vista, los métodos y los criterios desde los cuales se construyen dichos relatos e historias.
} 
Una de las primeras consideraciones que aparecen en el tratamiento de la Poética se vincula a la importancia y la influencia que tanto esta obra como la Retórica ejercieron en la cultura occidental, influencia que resulta sorprendente, si se tiene en cuenta que las temáticas allí abordadas se alejarían de las preocupaciones filosóficas más centrales de Aristóteles. ${ }^{5}$

Otra característica común, que podría derivarse de esta última afirmación, es el tipo de exposición que realizan de los tópicos de dichas obras. En primer lugar, la mayoría muestra un interés más pronunciado por Poética que por Retórica. Esto se encontraría justificado, quizás, como afirma Ross, por el mayor grado de vivacidad de la primera ([1923] 1995: 290); o por la profundidad alcanzada en el análisis del estilo literario, según Lloyd ([1968] 2008: 199); o porque, tal como se deduce de la lectura de Brun y de Moreau, la Poética se encontraría más próxima a una auténtica "teoría de la creación" o a un acabado "tratado sobre literatura" que la propia Retórica (Brun [1961] 1970: 131-134; Moreau [1962] 1972: 241).

No solo el breve abordaje de las obras es algo en lo cual conviene reparar, sino que también lo es, a mi entender, el tono escolar y altamente simplificador en el que se presentan sus aportes teóricos más relevantes. Con relación a la Poética, particularmente, Brun, Moreau y Barnes, por ejemplo, exponen escuetamente la clasificación de las artes como imitaciones; el origen de la poesía, la caracterización de la comedia y la definición de tragedia, y solo señalan como punto problemático la falta de precisiones que Aristóteles brinda acerca del tema de la kátharsis (Brun [1961] 1970: 133; Moreau [1962] 1972: 247-248; Barnes [1982] 1999: 140). Por su parte, Ross ([1923] 1995: 327-344), Düring ([1966] 2005: 256-289) y Lloyd ([1968] 2008: 200-206), hacen una presentación más profunda de los temas que son objeto de análisis de la Poética, pero la forma sistemática de presentarlos genera la imagen de un texto con una unidad, claridad e integración de las que lamentablemente carece el escrito aristotélico, por las propias condiciones en las que este fue elaborado.

La Poética es obra de un filósofo y, aunque resulte una obviedad, es necesario reparar en ello, si se pretende una comprensión de las ideas plasmadas por Aristóteles en este breve escrito. ${ }^{6}$ Halliwell advierte que esta

\footnotetext{
${ }^{5}$ Kaufmann advierte que "ningún otro libro ha influido tanto en las reflexiones sobre la tragedia y en la tragedia misma como las primeras quince secciones de la Poética de Aristóteles. Y cada sección tiene la extensión media de una página. Sin embargo, la Poética es sumamente afilosófica (...)" ([1968] 1978: 65).

${ }^{6}$ Bobes, Baamonde, Cueto et al. advierten que "hay en la obra una investigación sobre el arte literario desde el punto de vista de un filósofo (...). No obstante, no es un texto filosófico
} 
aclaración y la contextualización necesaria ${ }^{7}$ de la obra en un marco más amplio que incluya ideas, métodos y valores "debería ser, pero en los hechos no lo es, un lugar común" (1998: 2). Considero que esta contextualización bien puede articularse con una propuesta metodológica que asuma que los conceptos de la Poética forman un "campo de presencia" propio de un entramado histórico, en el que los elementos recurrentes de los enunciados pueden "reaparecer, disociarse, descomponerse, ganar en extensión o en determinación, volver a ser tomados en el interior de nuevas organizaciones lógicas, adquirir en desquite nuevos contenidos semánticos, constituir entre ellos organizaciones parciales" (Foucault [1969] 2006: 98). Con estos recaudos, abordaré el texto en general y la relación phýsis-tékhne será el prisma que permita poner en juego los aportes de las dos lecturas, la filosófica y la literaria.

\section{Apuestas múltiples en Poética o de cómo combinar tres perspectivas y dos momentos}

Zn un contexto como el actual, signado por una "crisis de las huciplinares son puestos fuertemente en discusión, preguntarse por la literatura sin caer en un discurso segregacionista, que impone cánones y distinciones entre "buena" y "mala" literatura para legitimar su propia existencia, resulta imperioso. Con una preocupación similar a la que proyecta sobre la constitución de la teoría del arte, Schaeffer se ocupa de dicha tarea en ¿Qué es un género literario? (1989) y en Pequeña ecología de los estudios literarios ¿Por qué y cómo estudiar la literatura? (2011). En ellos, a pesar de la distancia temporal en la escritura, se repite el ejercicio de pensar las relaciones entre géneros, literatura, artes y prácticas culturales, asumiendo las dificultades epistemológicas que la tarea impone.

En ambas obras, la Poética de Aristóteles se erige en ese lugar común de piedra de toque fundamental para los estudios literarios. La referencia al proyecto del Estagirita sirve para denunciar un problema epistemológico que se encuentra a la base de la autoproclamada "crisis de las humanidades" y que se vincula a un solapamiento de niveles, funciones o pretensiones de

porque no afronta de un modo radical los problemas de concepto y de relación de los temas que trata" (1995: 87).

${ }^{7}$ Una reedición de la discusión entre una mirada internalista y una contextualizadora de la Poética puede encontrarse en el artículo de B. Boulay 2016: 78-79. 
la literatura, en particular, y las ciencias humanas, en general. Una primera función es la de reproducción y promoción de los valores culturales de una sociedad. Desde esta perspectiva, estudiar la literatura o las humanidades es participar en un proyecto normativista. La segunda función de los estudios literarios es estrictamente cognitiva, por lo cual el afán por conocer las realidades literarias supone asumir un compromiso con un proyecto descriptivista. El problema, según Schaffer, es que esta dualidad constitutiva pocas veces es reconocida. Así,

si a la crisis de legitimidad actual de los estudios literarios se le suma una crisis epistemológica, esto se debe principalmente - como ya lo he indicadoa nuestra incapacidad recurrente para encontrar una salida a este dilema estatutario, que nos obliga a asegurar a la vez dos misiones que divergen fuertemente en sus presupuestos, objetivos, medios y resultados (Schaeffer [2011] 2013: 45).

Schaeffer refiere a la Poética como la primera obra en la que estos dos niveles o misiones aparecen superpuestos. ${ }^{8}$ Aristóteles justifica su jerarquía evaluativa haciendo referencia a lo "propio" del género trágico como aquello que corresponde a su naturaleza (phýsis). A este esquema, que le permite una evaluación tanto de las obras individuales como del género trágico, el Estagirita añade una concepción finalista de la evolución histórica del género. Esto plantea las tres perspectivas que se cuestionaron en ¿Qué es un género literario? Acuerdo con la presencia transversal de las perspectivas naturalista-esencialista, histórica-analítica y normativa del género trágico a toda la Poética. A los fines de este trabajo, me interesa llamar la atención sobre dos momentos en particular. El primero se extiende desde las primeras líneas de la obra y abarca los tres primeros capítulos (1447a-1448b) y el segundo está constituido por el capítulo IV (1448b4-1449a30), en el que se analizan las causas y el origen de la poesía. En lo que sigue, presentaré algunos lineamientos sobre cada una de las perspectivas, atendiendo a su desarrollo en los dos momentos elegidos de la obra.

\footnotetext{
${ }^{8}$ Los aspectos centrales de la crítica al papel desempeñado por la Poética que aquí reconstruyo se reproducen también en la entrada "géneros literarios" del Nuevo diccionario enciclopédico de las ciencias del lenguaje (Ducrot y Schaeffer [1995] 1998).
} 


\section{La Poética en el microscopio o de cómo se construye una mirada naturalista sobre la tékhne}

1 tono naturalista-esencialista con el que Aristóteles analiza el fe-
nómeno poético está presente, como mencioné, a lo largo de toda la Poética. En particular, me interesa señalar en los dos momentos elegidos (1447a-1448b y 1448b-1449a) los elementos que cimientan dicha perspectiva. El Estagirita comienza la Poética trazando un condensado plan, que omite toda vinculación entre los objetivos de esta obra y el resto del corpus, y entre el tipo de conocimiento que de aquí pueda obtenerse y los restantes niveles o formas de conocimiento (véase Else 1957: 2; Dolězel [1990] 1997: 32). Así, propone que:

Hablemos de la poética en sí y de sus especies, de la potencia propia de cada una (dýnamin),y de cómo es preciso construir las fábulas [sintetizar las tramas] (synistasthai toùs mýthous) si se quiere que la composición poética (he poíesis) resulte bien [bella] (kalôs), y asimismo del número y naturaleza de sus partes e igualmente de las demás cosas pertenecientes a la misma investigación, comenzando primero, como es natural (katà phýsin), por las primeras. Pues bien, la epopeya y la poesía trágica y también la comedia y la ditirámbica, y en su mayor parte la aulética, y la citarística, todas vienen a ser, en conjunto, imitaciones (miméseis). Pero se diferencian entre sí por tres cosas: o por imitar con medios diversos, o por imitar objetos diversos, o por imitarlos diversamente y no del mismo modo (1447a8-18).

De esta manera inicia el tratado, casi en forma inductiva, enumerando las artes más diversas e incluyéndolas bajo un común denominador. El procedimiento empleado en este pasaje inicial se asemeja al de un naturalista que se aproxima por primera vez a su objeto de estudio y que al hacerlo establece, por un lado, una identidad sustancial para cada una de las especies poéticas y, por otro, una relación entre dichas especies poéticas y la mímesis como rasgo genérico común. En las primeras líneas del pasaje, la tékhne aparece como sujeto tácito. ${ }^{9}$ Hablar de la "poética en sí" (Perì poietikês autês) es reconocer la posibilidad de la poética como tékhne, como una actividad intelectual particular que es capaz de combinar medios racionales y cognoscibles para el logro de fines predetermi-

\footnotetext{
${ }^{9}$ Ricoeur señala, en el mismo sentido, que el sustantivo "arte” está sobrentendido en el adjetivo “poética” ([1985] 1995: 82).
} 
nados. ${ }^{10}$ Es a partir de dicha consideración que la poética aparece como el género que nuclea diferentes especies y la mímesis como el común denominador entre ellas. El método, dirá Schaeffer ([1989] 2006: 9), es el de un "acercamiento en árbol que va del génos (género) al eîdos (especie) por medio de definiciones que determinan las diferencias específicas de los diversos eíde".

Las distinciones entre las expresiones artísticas (según los medios, los objetos y los modos de imitar) son asumidas como naturales "como si fuera algo absolutamente normal el hecho de postular que el ámbito literario se organiza según un orden natural. Uno no puede por menos que quedarse perplejo delante de esta fuerza de evidencia del modelo biológico (...)" (Schaeffer [1989] 2006: 9). Aquí se produce una primera tensión entre phýsis y tékhne, en tanto opera un procedimiento esencialista de paradigma biológico que asume que una serie de producciones humanas contingentes tienen una forma y finalidad interna propias y que responden a cierta naturaleza o "sustancializacion" de los géneros. ${ }^{11}$

Donini (1997: 327) sostiene, en este mismo sentido, que el arte debe ser enmarcado dentro del ámbito de la generación y la producción teleológica, pues en la creación artística se copia o imita la estructura inherente a los procesos naturales. ${ }^{12}$ De esto se deriva que el arte actúa siguiendo una estructura que resulta anterior y que excede la propia voluntad del poeta, por lo que las 340 I producciones artísticas resultan, en cierto sentido, equivalentes a las naturales. $\mathrm{Al}$ respecto, conviene recordar el paralelismo trazado por el propio Estagirita entre phýsis y tékhne en Física 199a15-17, en donde afirma que "el arte lleva a cabo aquellas cosas que la naturaleza es incapaz de realizar [de completar] (epitelề) y, además, imita a la naturaleza (tà dè mimeîtai)" y en el fragmento 14 del Protréptico en el que se advierte que "si el arte imita a la naturaleza (Ei toínun he tékhne mimeîtai tèn phýsin), de esta se ha derivado también el hecho de que toda generación en el ámbito de las artes se produzca con vistas a algo (apò taútes ekoloútheke kaì taîs tékhnais tò tèn génesin háposan héneká tou gígnesthai)"(B 14 1-3).

${ }^{10}$ Tal como se infiere de las referencias de Metafísica 1025b 25; Ética Nicomáquea 1140a 1-22 y Tópicos 145a 16-18.

${ }^{11}$ Para que esta "sustancialización" sea posible se debe asumir una concepción de phýsis como ousía o eîdos, en el sentido de lo expuesto en Física 193a30: "la naturaleza es la forma (morphé) y su determinación conceptual específica (eîdos)", o en Metafísica 1015a10-11: "[y es naturaleza (phýsis)] también la especie (eîdos) y la substancia (ousía); y este es el fin de la generación (estì tò télos tês genéseos). Agradezco a la Dra. Seggiaro su comentario al respecto.

${ }^{12}$ Petit refiere a que se trata de un movimiento analógico controvertido y que "uno de los problemas más espinosos que tenemos que plantearnos aquí reside precisamente en la transferencia a la naturaleza de los atributos del arte, y sobre todo en la legitimidad de dicha transferencia" (1997: 37). 
En el segundo momento, cuando Aristóteles centra su atención en las causas que dieron origen a la poesía, desarrolla el mismo proceder metodológico que sigue cuando se trata de temas susceptibles de una investigación empírica. El pasaje de 1448b4-17 está teñido de un lenguaje naturalista que, por un lado, permite ubicar a la poesía (tékhne) en el ámbito de la naturaleza (phýsis) y, por otro, logra sentar las bases para una visión orgánica de la descripción del nacimiento, desarrollo y evolución de las especies poéticas (véase Suñol 2012: 70). Allí, Aristóteles señala que:

Parecen haber dado origen (gennêsai) a la poética fundamentalmente dos causas (aitíai), y ambas naturales (physikai). El imitar (tò mimeîsthai), en efecto, es connatural (sýmphyton) al hombre desde la niñez, y se diferencia de los demás animales (tôn állon zóon) en que es muy inclinado a la imitación (mimetikótaton) y por la imitación adquiere sus primeros conocimientos y también el que todos disfruten con las obras de imitación.Y es prueba de esto lo que sucede en la práctica; pues hay seres cuyo aspecto real nos molesta, pero nos gusta ver su imagen (tàs eikónas) ejecutada con la mayor fidelidad posible, por ejemplo, figuras de los animales más repugnantes y de cadáveres.Y también es causa (aítion) de esto que aprender (manthánein) agrada muchísimo no solo a los filósofos, sino igualmente a los demás, aunque lo comparten escasamente. Por eso, en efecto, disfrutan viendo las imágenes (tàs eikónas), pues sucede que, al contemplarlas (theoroûntas), aprenden y deducen (manthánein kaì syllogízesthai) qué es cada cosa (tí hékaston), por ejemplo, que este es aquel (hoûtos ekeinos) (1448b4-17).

Aristóteles articula en este pasaje un origen natural de la poesía con la posesión de una habilidad que permite el aprendizaje. ${ }^{13}$ Por ello afirma, primeramente, que la poesía surge porque el hombre es un ser mimético por naturaleza, en cuanto es dotado de la mímesis como una habilidad o disposición desde el momento mismo de su nacimiento (sýmphyton, 1448b5-6). Luego, reconoce que la mímesis es una habilidad que se encuentra en otros animales (tôn állon zóon, véase Investigación sobre los animales 597b24-30; 612b17-35), pero el grado de desarrollo que alcanza en el hombre es lo que traza la diferencia y, en tal sentido, el hombre es caracterizado como el más mimético de todos (mimetikótaton, Poética 1448b7). Finalmente señala, desde

${ }^{13}$ Sobre las implicaciones éticas y políticas de esta articulación, véase Castillo Merlo (2014, 2015, 2016 y 2020a y b). Agradezco a los/las evaluadores/as del artículo las sugerencias para revisar el trabajo, en un sentido similar, de $\mathrm{M}$. Leunissen, quien incorpora al aprendizaje mimético como un proceso de habituación ético-político (2017: 119-120). 
una perspectiva teleológica, la finalidad que tiene esta habilidad: por un lado, permitir la adquisición del conocimiento, en cuanto la mímesis promueve un aprendizaje (manthánein) basado en la observación y el reconocimiento (Poética 1448b16-17), por otro, estimular de manera hedonista dicho aprendizaje, ${ }^{14}$ en la medida en que la mímesis permite el deleite (khaíro) a través de las imágenes o de aquello que es "puesto ante los ojos" (Poética 1448b15 y $1448 \mathrm{~b} 19) \cdot{ }^{15}$

\section{El cronista ideal de Poética o de cómo construir una historia retrospectiva}

- $\mathrm{n}$ Analitical Philosophy of History (1965), Danto propone la figura

Cdel cronista ideal y el concepto de oraciones narrativas. El cronista ideal es aquel que conoce todo lo que sucede, en el momento que sucede y puede hacer una exacta transcripción de los acontecimientos. La crónica ideal sería la descripción de todo lo que ocurrió, un duplicado del pasado y, aun así, resultaría una crónica incompleta. ¿Cuál es la razón de su falencia? Según Danto, el problema estriba en que dicho cronista es incapaz de utilizar aquellas expresiones que son el rasgo característico de cualquier discurso histórico: las "oraciones narrativas". Dichas oraciones son descripciones retrospectivas de un acontecimiento $\mathrm{X}$ a la luz de otro acontecimiento X1 ocurrido posteriormente.

El historiador, por encontrarse en el presente y tener la posibilidad de contar retrospectivamente los acontecimientos que ocurrieron después de aquel que está investigando, tiene un privilegio epistémico que le permite organizar e interpretar el pasado histórico. La pregunta que surge frente a estas consideraciones es si resulta posible distinguir entre la "pura" descripción de los hechos y la "interpretación" que hacemos de ellos. Para Danto, la respuesta es negativa porque "la historia es de una sola pieza", toda descripción interpreta, toda narración requiere y supone criterios de relevancia y sin esos criterios de selección no hay historia posible (Danto [1965] 1989: 85). En otras palabras,

\footnotetext{
${ }^{14}$ Mouza (2003: 488, énfasis en el original) señala que "el objetivo de la tragedia es suscitar el placer [de naturaleza intelectual], vía estas emociones [de compasión y temor], es decir que el objetivo de la tragedia es, en un principio, hedonista".

${ }^{15}$ Afirmaciones similares del Estagirita se encuentran en Metafísica 980a 21 donde afirma que "todos los hombres desean (orégontai) por naturaleza saber (toû eidénai)" y en Retórica 1410b10-11, "un fácil aprendizaje (manthánein) es, por naturaleza, placentero (hedý) a todos”.
} 
La historia solo la podemos conocer desde dentro, somos sujetos históricamente situados en el momento posterior a los hechos relatados. Así las historias que contamos dicen tanto de nuestro pasado, como de nuestros intereses presentes: en cierto sentido, somos un microcosmos de las historias que somos capaces de narrar (Birulés 1989: 26, énfasis en el original).

A partir de estas consideraciones, la perspectiva histórico-analítica que Aristóteles proyecta sobre el fenómeno poético cobra un nuevo sentido. El período de madurez de la obra aristotélica, en el que la mayoría de los estudiosos de la Poética coincide en ubicar su redacción, parece estar signado por las investigaciones empíricas. Así, del mismo modo que escribir su Política supuso la recopilación de las constituciones disponibles en aquel entonces, el estudio que emprende sobre la tragedia no parece una tarea improvisada. Según registra Jaeger ([1946] 2001: 372-377), hacia el 335-334, Aristóteles escribió, en colaboración con su sobrino Calístenes, una Lista de los Vencedores Píticos y por la misma época parece haber investigado (y escrito, según apunta Diógenes Laercio, en su Vidas (V.1)) sobre las competencias que se llevaban a cabo en Las Grandes Dionisíacas y las Leneas. Junto con estos estudios, también escribió sus Didascalias, que constituían archivos que sirvieron para datar los estrenos de las piezas teatrales en Atenas y fueron la fuente histórica que los alejandrinos utilizaron para formular una historia del teatro clásico. ${ }^{16}$

En el primer momento de la Poética (1447a-1448b), Aristóteles pone de manifiesto su conocimiento sobre la temática y se ocupa, principalmente, de desplegar los resultados de su labor documentalista sobre el desarrollo, modificaciones y referentes de las distintas artes, según los medios, los objetos y los modos en que llevan a cabo las imitaciones. Aunque a primera vista se asemeja a un cronista ideal, en términos de Danto, la descripción que presenta le permite ir, progresivamente, construyendo parámetros para su análisis de la tragedia. Esto resulta claro, por ejemplo, en el pasaje de 1448a1-19, en el que señala que:

Mas puesto que los que actúan imitan a hombres que actúan (mimoúmenoi práttontas) y estos necesariamente (anánke) serán esforzados (è spoudaíous) o de baja calidad (è phaúlous) (...), o bien los hacen mejores que solemos ser nosotros, o bien peores o incluso iguales, lo mismo que los pintores. Polignoto,

${ }^{16}$ Véase Hardy 1952: 13-14; Lucas 1968: xiii; Barnes [1982] 1999: 20-21; Düring [1966] 2005: 207 y Halliwell 1998: 324-328. Para este último autor, nada en la Poética hace presuponer indubitablemente las Didascalias, aunque algunos pasajes puedan insinuar lo contrario. 
en efecto, los pintaba mejores (kreíttous); Pausón, peores (kheírous), y Dionisio, semejantes (homoíous eíkazen). (...).

Pues también en la danza y en la música de flauta y en la cítara pueden producirse estas desemejanzas (genésthai taútas tàs hanomoiótetas), así como en la prosa y en los versos solos; por ejemplo, Homero hace a los hombres mejores; Cleofonte, semejantes y Hegemón de Taso, inventor de la parodia, y Nicócares, autor de la Dilíada, peores. (...).

Y la misma diferencia (tê diaphorâi) separa también a la tragedia de la comedia; esta, en efecto, tiende a imitarlos peores (kheírous), y aquella, mejores que los hombres reales (beltíous mimeîsthai tôn nûn).

En este pasaje, Aristóteles no solo describe las diferencias entre los géneros poéticos de acuerdo con los objetos imitados, sino que muestra -y asume- que dicha distinción histórica y aparentemente natural es la que permite diferenciar la tragedia de la comedia.Volveré sobre las implicancias normativas de este pasaje más adelante. Por ahora, basta señalar, siguiendo a Dolězel ([1990] 1997: 34-35), que "si aceptamos la idea de que la poética de Aristóteles es una ciencia productiva, el próximo paso será determinar si satisface y cómo los postulados generales de la filosofía de la ciencia de Aristóteles". Eso implicaría a) mostrar los atributos esenciales de los géneros poéticos; b) utilizar la inducción para pasar de los particulares a los universales y c) organizar el conocimiento según los principios de la demostración. Para el autor, en la formación de un modelo de tragedia, Aristóteles pondría en juego tres procedimientos lógicamente distintos: la inferencia, el análisis mereológico y la división. Las categorías universales del género trágico se disponen de acuerdo con un modelo estratificacional que se complementa con un modelo mereológico basado en dos postulados: el de la no adicionalidad (el todo es más que la suma de sus partes) y el de la totalidad (toda categoría superior es reemplazada por un conjunto necesario y exhaustivo de sus constituyentes). Desde esta perspectiva, se establece una serie de relaciones estructurales y funcionales entre la poética y sus especies, en el estudio de las propiedades emergentes, en las jerarquías estructurales ligadas por la derivación y la integración, etc. que no solo reviste de importancia histórica, ${ }^{17}$ sino que estaría a la base del desarrollo epistemológico que fundamenta, en última instancia, un estudio de la poética en tanto tékhne.

\footnotetext{
${ }^{17}$ Para Dolězel “al otorgar a Aristóteles la oportunidad de demostrar el análisis mereológico, la poética adquiere -junto con la ciencia de los organismos vivos- una importancia histórica para el desarrollo de la epistemología científica. El estudio de las estructuras poéticas se convierte en fuente de inspiración para los estudios estructurales en general” ([1990] 1997: 45).
} 
En el segundo momento, la figura del aparente cronista ideal que se configuró en la primera parte de Poética se transforma en un verdadero historiador del género trágico. Aristóteles relata una genealogía de la tragedia a partir del uso de "oraciones narrativas". En 1449a señala que:

Habiendo, pues, nacido al principio (ap' arkhês) como improvisación (autoschediastikés) -tanto ella como la comedia; una, gracias a los que entonaban el ditirambo (tôn exarkhónton tòn dithýrambon), y la otra, a los que iniciaban los cantos fálicos (tôn tà phaliká), que todavía permanecen vigentes en muchas ciudades-, fue tomando cuerpo, al desarrollar sus cultivadores (proagónton) todo lo que de ella iba apareciendo; y, después de sufrir muchos cambios (pollàs metabolás), la tragedia se detuvo (epaúsato), una vez que alcanzó su propia naturaleza (tèn autês phýsin) (Poética 1449a9-15).

En este contexto, Aristóteles expone, bajo una perspectiva teleológica, los distintos estadios por los que transitó la tragedia. En primer lugar, se señala un origen común para la comedia y la tragedia, esto es, ambas se deben a las improvisaciones, ya sean en forma de ditirambos, para el caso de la tragedia, o de cantos fálicos, en el de la comedia. Un segundo momento está signado por una multiplicidad de cambios de los que Aristóteles dará cuenta unas líneas después del pasaje en cuestión y que se relacionan con el número de actores, la posición y función del coro, la escenografia, la métrica utilizada en los versos, etc. (véase Poética 1449a 16-30). Finalmente, la tragedia parece haber alcanzado la forma que le es propia y allí el proceso se detuvo, aunque el propio Estagirita había eludido previamente la cuestión de "si la tragedia ha alcanzado ya su pleno desarrollo (tô̂s eídesin hikanôs), tanto si esto se juzga en sí mismo como en relación con el teatro" (Poética 1449a7-9).

Aristóteles narra el desarrollo de la tragedia, haciendo uso de lo que, en términos de Danto, es la herramienta fundamental para dicha tarea, esto es, las oraciones narrativas. Así, desde un momento posterior, selecciona cuáles fueron aquellos acontecimientos que permitieron configurar la tragedia y establece relaciones de causalidad y necesidad entre ellos. En dicha narración, se destacan nuevamente el tono naturalista y finalista $y$, en contrapartida a la dificultad que supone determinar el principio de la tragedia, Aristóteles impone una perspectiva que se centra en el estadio final, en el télos trágico. Lo importante (y de lo que efectivamente se ocupará el Estagirita a lo largo de su Poética) es del análisis de la naturaleza de la tragedia, de su phýsis, y esta es abordada desde una perspectiva teleológica. Si se tiene en cuenta 
el principio según el cual "la naturaleza es fin" ${ }^{18}$ en el caso de la tragedia, Aristóteles parece estar suponiendo que, aun cuando no pueda afirmarse con certeza que se trata de la forma más acabada de tragedia, el estado en el que se encuentra, cuando él escribe, permitiría suponer que su potencialidad se ha realizado, al menos en términos teóricos (Else 1957: 153; Lucas 1968: 82; Halliwell 1998: 94; Schaeffer [1989] 2006: 16).

La perspectiva teleológica que Aristóteles le imprime a su descripción histórica de la tragedia pone nuevamente en tensión la dupla naturaleza-arte, phýsis y tékhne. En un sentido semejante a lo expuesto en Física 199a15-17 y en los fragmentos 13 y 14 del Protréptico, arte y naturaleza parecen llevar a cabo un trabajo cooperativo. Por un lado, la tragedia es una tékhne particular que fue variando su configuración, gracias a los cambios y modificaciones que introdujeron los distintos artistas a lo largo de su desarrollo. Por otro lado, la tragedia parece tener una phýsis propia, con un fin determinado, que dotó a dichos cambios y modificaciones de un ordenamiento particular, y logró que la tragedia alcanzara su estadio actual. Schaeffer advierte dicha tensión y señala que si bien la distinción phýsis-tékhne está presente en la mayoría de los textos aristotélicos, desde una perspectiva esencialista de corte biológico, en Poética, en cambio, las fronteras desaparecen "signo, si aún quedaba duda al respecto, de la fragilidad de la distinción, claramente establecida por lo demás, entre los artefactos, objetos con finalidad puramente externa, y los objetos naturales, que poseen una finalidad interna" ([1989] 2006: 16-17).

La posible analogía entre los pasajes de Física, el Protréptico y Poética radica, a mi entender, en la afirmación de un modo de obrar teleológico en el desarrollo histórico de la tragedia. Esto implica que el arte (tékhne) copia o completa (epitelein) una estructura inherente a los procesos naturales (phýsis), que ubica a la producción artística como un momento más en el desarrollo teleológico de los entes contingentes y sometidos al devenir. La tragedia actúa siguiendo una estructura que resulta anterior y que excede la producción de los artistas. Al tomar como modelo a lo natural, el arte imita su modo de actuar, pero también lo mejora y lo completa (Física 199a15-17, Protréptico fragmentos 13 y 14). En este sentido, se revela una tensión en el seno de la historia de la tragedia entre un determinismo, que proviene de la

\footnotetext{
${ }^{18}$ Véase Política 1252b32-33, donde Aristóteles afirma que "la naturaleza es fin (he dè phýsis télos estín). En efecto, llamamos naturaleza de cada cosa a lo que cada una es (taúten phamèn tèn phúsin eînai hekástou), una vez acabada su generación (genéseos telestheíses)" y Física 199a78 , en donde se articula la premisa al argumento que establece la similitud entre el proceder teleológico natural y artístico: "la finalidad entra en las cosas que son y se generan por naturaleza" (éstin ára tò héneká tou en tô̂s phýsei gignoménois kaì oûsin).
} 
estructura teleológica que se le impone, y las modificaciones contingentes introducidas por una serie de artistas a lo largo de dicha historia.

Asimismo, esa misma tensión entre phýsis y tékhne es lo que evita que la reconstrucción que realiza Aristóteles pueda ser interpretada como una mera reconstrucción anacrónica, que dota de sentido a lo que no es más que una sucesión de cambios contingentes e innovaciones casuales introducidas al azar, y pueda ser una verdadera narración histórica. Como advierte Halliwell (1998: 95), no existe riesgo de anacronismo, en la medida que la relación entre una visión naturalista/teleológica y el entendimiento histórico contingente del desarrollo cultural de la tragedia se asiente en la distinción, central en el siglo $\mathrm{V}$ a.C., entre naturaleza (phýsis) y tradición, continuidad cultural y convención humana (nómos). A mi entender, este anclaje le permite a Aristóteles narrar la genealogía de una práctica cultural, cuyo propósito es comprender las relaciones, las continuidades y las rupturas con otras prácticas y formas poéticas.

\section{La normatividad en Poética o sobre cómo construir cánones para siempre}

T as interpretaciones "filosófica"y "literaria" de la Poética coinciden y última perspectiva de análisis, que tiñe completamente la obra. La discusión se abre al momento de determinar su finalidad.Ya sea que trate de decirnos "cómo producir una [obra de arte]" (Barnes [1982] 1999: 139); o "[cómo es] el arte de los poetas en cuanto tal” (Düring [1966] 2005: 262); o "cuáles son los elementos que conforman una buena tragedia y por qué" (Lloyd [1968] 2008: 200); o "[cómo] realizar una clasificación de las obras para ejercer la crítica literaria” (Garrido Gallardo, 1988: 11); o "[cómo valorar] la forma y eficacia de la gran poesía” (Lesky [1963] 1989: 600); o “[cómo trabajar en] la reacción de la audiencia” (Kaufmann [1968] 1978: 146); lo innegable, y que queda por fuera de toda discusión, es el carácter fuertemente valorativo que Aristóteles le imprime a su proyecto.

Al respecto, me serviré, en un intento por comprender la función normativa de Poética sin caer en la falacia naturalista, del concepto de "normativismo naturalizado" formulado por Larry Laudan (1987). Si bien se trata de una propuesta meta-metodológica, a los fines de este trabajo, me permite mostrar una articulación posible entre las perspectivas naturalista-esencialista, histórica-analítica y normativa. En principio, Laudan rechaza la idea de que las normas tengan un carácter a priori o absoluto. Las normas son entendidas como imperativos hipotéticos aceptados inductivamente a partir de la evi- 
dencia empírica. Es decir, en un sentido tienen un carácter a priori, en tanto son condición de posibilidad de los juicios de valor, pero es un a priori relativo e histórico, que incluye la idea de que las normas están condicionadas históricamente. Si aplicamos la propuesta de Laudan a Poética, podría afirmarse que "una metodología meticulosamente 'científica' y robustamente 'descripta' tendrá consecuencias normativas" (Laudan 1987: 25). De esta manera, la Poética puede ser vista como un proyecto de tékhne, que configura una narración histórica basada en una descripción analítica de la amplia evidencia empírica recolectada (desde una perspectiva naturalista-esencialista propia de la filosofía aristotélica), y tiene como consecuencia necesaria la elaboración de criterios normativos a partir de los cuales se evalúan otras producciones poéticas. Si aceptamos esta propuesta, el riesgo, siempre presente, es confundir descripción y norma. Pero, como advierte Schaeffer,

para poder deducir un criterio de identificación de una supuesta "naturaleza" literaria, ya se debe de haber formulado (tácitamente) un juicio de preferencia sobre las propiedades valorizadas. Y desde entonces, la supuesta determinación de la "naturaleza" de la literatura, lejos de estar "dada" de antemano, queda determinada con posterioridad, a partir de tal criterio axiológico ([2011] 2013: 51, énfasis en el original).

Para ilustrar este problema, volveré sobre los dos momentos elegidos para el análisis (1447a-1448b y 1448b-1449a). Desde el comienzo de la obra, Aristóteles expone su enfoque normativo, al advertir que hablará:

de la poética en sí y de sus especies, de la potencia propia de cada una (dýnamin) y de cómo es preciso (dề) construir las fábulas [sintetizar las tramas] (synístasthai toùs mýthous), si se quiere que la composición poética (he poíesis) resulte bien [bella] (kalôs), y asimismo del número y naturaleza de sus partes e igualmente de las demás cosas pertenecientes a la misma investigación, comenzando primero, como es natural (katà phýsin), por las primeras (1447a8-13).

En el íncipit, Aristóteles asume un tono normativo que instaura, en un mismo movimiento, la posibilidad de la poética como tékhne y como poíesis, como la resultante de una actividad humana productiva basada en conocimientos particulares, y el sentido y la función de los mŷthoi para la tragedia. Schaeffer llama la atención sobre el uso del impersonal dề en este contexto, y a lo largo de Poética, como un rastro lingüístico de la actitud normativa que recorre la obra y que adquiere mayor impronta al momento de definir la tragedia (1449b 24-31) y determinar las cualidades y operaciones que deben realizarse para su prosecución. Así "vemos perfectamente que 
Aristóteles aquí no se limita a analizar los mŷthoi posibles o reales sino que prescribe los rasgos que debe poseer un mŷthos acertado" (Schaeffer [1989] 2006: 10). El objetivo de Poética no es meramente descriptivo, sino también normativo: interesa no solo conocer cómo son actualmente las tragedias, sino cómo deberían ser para ser consideradas "buenas/bellas" tragedias.

En tal sentido, la tarea descriptiva llevada a cabo por Aristóteles da lugar a una serie de criterios normativos, que podrían dividirse en dos grandes ámbitos: 1) los que permiten alcanzar la finalidad de las tragedias; y 2) los que atañen a la construcción del mímema. La adecuada combinación de estos ámbitos asegura, en gran medida, el éxito de una obra dramática. Los primeros se vinculan directamente con el contenido de las obras, y los segundos con su forma. En tal sentido, Schaeffer advierte que "todas las prescripciones de forma y de contenido permanecen íntimamente relacionadas con el efecto de la tragedia: la catharsis" ([1989] 2006: 10). Ahora bien, si concedemos una evaluación pragmática de la finalidad de la tragedia, las preguntas que surgen refieren tanto al status como al carácter de dicha finalidad. En palabras de Schaeffer la cuestión a resolver estriba en saber si:

¿se trata de una finalidad inherente a la tragedia como tal, o de una finalidad externa, es decir, exigida por la sociedad ateniense o por el filósofo Aristóteles? Esta cuestión no es sino un aspecto concreto de aquel otro problema más general: ¿puede un acto de lenguaje tener una finalidad interna? Ahora bien, varias veces nos parece que Aristóteles tiene tendencia a ver en la catarsis una finalidad inherente a la tragedia, o lo que es lo mismo, a suponerle una naturaleza y a tratarla como una sustancia. Actuando así, pasa del normativismo al esencialismo ([1989] 2006, 10).

Dejaré las preguntas planteadas para pasar al segundo momento. Allí, siguiendo la perspectiva teleológica mencionada anteriormente, Aristóteles asume una ordenación cronológica y ontológica de las especies de poesía, en la que una (la tragedia) resulta la culminación y el perfeccionamiento de la otra (la épica). La aparición de la tragedia supuso una evolución respecto de la poesía épica, no solo en términos histórico-literarios sino, principalmente, en términos morales. Así, luego de señalar las causas de la poesía, afirma que:

Siéndonos, pues, natural (katà phýsin) el imitar, así como la armonía y el ritmo (pues es evidente que los metros son partes de los ritmos), desde el principio (ex arkhês) los mejores dotados para estas cosas, avanzando poco a poco, engendraron la poesía (egénnesan tèn poíesin) partiendo de las improvisaciones. Pero la poesía se dividió según los caracteres particulares: en efecto, los más graves (hoi mèn semnóteroi) imitaban las acciones nobles (tàs kalàs práxeis) y las 
de los hombres de alta calidad, y los más vulgares (hoi eutelésteroi), las de los hombres inferiores (tàs tôn phaúlon), empezando por componer invectivas del mismo modo que los otros componían himnos y encomios (1448b20-27).

Este pasaje remite directamente a lo expresado anteriormente en 1448a17-19, donde Aristóteles clasificó las artes, tomando como criterio el tipo de objeto imitado. Nuevamente se postula una perspectiva naturalista para explicar la evolución de los géneros poéticos. En la primera parte, la habilidad connatural para la imitación descripta en 1448b4-5 se conjuga con la armonía y el ritmo, como cualidades del lenguaje, y con la existencia de un grupo de personas naturalmente mejor dotadas para la producción poética. La reconstrucción histórica del Estagirita remite de muchas maneras a un desarrollo poético orgánico y evolutivo no solo por los términos empleados, sino también por los supuestos temporales y de complejidad implicados. De manera análoga a lo que ocurre con la generación en el ámbito de la naturaleza, la generación de la poesía demanda de ciertas condiciones: una materia (ciertas habilidades connaturales: la mímesis y el lenguaje); un motor (los mejores dotados para la poesía); una forma (improvisaciones, himnos y encomios, tragedia) y una finalidad (el aprendizaje y su placer concomitante). ${ }^{19}$

Una vez garantizadas las condiciones iniciales, el proceso avanza progresivamente dando lugar a la distinción natural entre comedia y tragedia. El razonamiento que sigue el Estagirita sobre dicha distinción se fundamenta en premisas de tipo general, según las cuales: a) todos los que imitan toman por objeto a sujetos en acción y, b) (todos) los sujetos no son moralmente indiferentes, sino son o bien esforzados/elevados (spoudaíous) o bien de baja calidad/ inferiores (phaúlous).$^{20}$ De dichas premisas se concluye que c) cada una de las especies miméticas tendrá estas diferencias (éxei taútas tàs diaphoràs) a raíz de sus objetos (y por ello serán o bien elevadas o bien inferiores) (Poética 1448a1-9).

La conclusión del argumento le permite a Aristóteles marcar una clara distinción entre la comedia y la tragedia, al afirmar que la primera quiere imitarlos "peores" (kheírous), mientras que la tragedia pretende hacerlos "me-

\footnotetext{
${ }^{19}$ Véanse Reproducción de los animales 715a1-13 y Física 193b12-13: "La naturaleza (phýsis) entendida como generación (génesis) es un tránsito a la naturaleza (phýsis) (propiamente dicha)”. ${ }^{20}$ Entre los estudiosos de la Poética (De Montmollin 1951: 25-29; Else 1957: 88-89; Halliwell 1987: 75-77), subsiste una discusión sobre la división bipartita del carácter pues, luego de afirmarla, Aristóteles sostiene que “...[los que imitan] o bien los hacen mejores (beltíonas) de lo que somos nosotros, o bien peores (kheíronas) o incluso iguales (toioútous)" (Poética 1448a 4-5). Una opción para salvar la aparente incongruencia del Estagirita es suponer, como hace Suñol 2012: 59, que está refiriéndose a dos cuestiones diversas: en primer lugar, a los caracteres de los actuantes y, en segundo término, a los posibles modos de representación.
} 
jores (beltíous) que los hombres reales" (1448a17-19). La argumentación que sustenta esta diferenciación de los géneros poéticos no deja de sorprender a estudiosos y comentadores (véanse Rodríguez Adrados 1972: 24;Veloso 2004: 102). Si bien las críticas a este movimiento son múltiples y atendibles, no debe perderse de vista cuál es la finalidad que persigue el Estagirita en este contexto y el sentido que este pasaje adquiere en la propia estructura de la Poética, al permitir trazar una genealogía de la tragedia a partir de formas poéticas consolidadas en la práctica cultural griega. De esta manera, resulta necesario sostener que la tragedia, al igual que la poesía épica, tiene por objeto hombres de una naturaleza moral más elevada, de carácter heroico, y que por ello "los poetas épicos se convirtieron en autores de tragedias, por ser estas formas de más fuste y más apreciadas que aquellas" (Poética 1449a 5-6).

Aristóteles establece, a partir de la descripción de la evolución de la tragedia, un criterio normativo acerca del objeto sobre el que recae la mímesis trágica. Para no caer en la falacia naturalista, en un pasaje del ser al deber ser que no puede ser justificado, conviene recordar la propuesta de un normativismo naturalizado. Así, el género "tragedia" al que Aristóteles le dedicará el resto de su Poética solo es definible en un contexto histórico particular. Los recaudos que el propio Estagirita toma al evitar responder "si la tragedia ha alcanzado ya su pleno desarrollo" (1449a 7-8), deberían haber resultado suficientes para cuestionar la conformación, a partir de su proyecto, de clasificaciones genéricas que se perpetuaron en la historia de la literatura y se erigieron como modélicas para toda la actividad poética futura. En este sentido, afirma Schaeffer:

lo que en Aristóteles no era, en resumidas cuentas, más que una tentación -a la que ciertamente él no se resistía siempre, sino contra la que él mismo disponía del argumento decisivo, a saber, la distinción entre objetos naturales dotados de una finalidad interna y objetos culturales sometidos a una finalidad externa- va a convertirse en la actitud dominante de la teoría literaria a partir del Romanticismo (...) ([1989] 2006: 25).

\section{Consideraciones finales}

Dara cerrar este paseo por los albores de la Poética, de la mano de la distinción phýsis y tékhne, me interesa subrayar, por un lado, la complejidad de la obra y la pluralidad de perspectivas que Aristóteles despliega y pone en juego en su investigación sobre el fenómeno poético y, por otro, la imposibilidad de trazar una distinción tajante entre phýsis y tékhne, entre la naturaleza y la actividad humana productiva. 
Desde esta posición, la crítica de Schaeffer ([1989] 2006: 7-17) a la ambigüedad de Aristóteles es ya, desde su propia formulación, una crítica imposible. Schaeffer reconoce la pluralidad de perspectivas y traza un breve resumen de las consecuencias que cada una de ellas ha tenido en la historia de los géneros literarios

esquematizando de manera caricatural, podríamos decir que la actitud normativa fue dominante hasta finales del siglo XVIII, que fue relevada posteriormente por la actitud esencialista-evolucionista, dominante hasta finales del siglo XIX, momento en que pasó el relevo a una recuperación del análisis estructural siguiendo en ello a los formalistas rusos ([1989] 2006: 17).

El problema entonces no es la riqueza y el juego de variables (irreductibles entre sí) que plantea Aristóteles, sino sus consecuencias en la historia de la literatura y el modo en que cada una de ellas sirvió a intereses diferentes en cada época. Cuando Schaeffer denuncia "las ambigüedades del padre fundador" denuncia, en parte, la imposibilidad de distinguir cada una de estas perspectivas, pero también denuncia la ausencia de una finalidad propia al género literario, lo que nos conduce de nuevo al problema de la relación phýsis-tékhne.

Nuevamente, no parece radicar en Aristóteles o en la Poética el problema de dicha relación sino en el intento posterior por establecer fronteras entre esas dos formas de creación y ocultar sus vasos comunicantes. Los lazos tejidos entre phýsis y tékhne al interior de la Poética muestran una concepción teleológica del mundo y la búsqueda de un sentido y función para la producción humana. En la concepción aristotélica resulta imposible desligar al hombre como parte de la phýsis y como origen de una tékhne que ponga en juego sus capacidades productivas.

Termino de escribir este trabajo en el marco de la pandemia por COVID-19. La realidad se impone y exige nuestra reflexión. Pienso en la Poética, en su historia, en sus vaivenes y en sus múltiples interpretaciones. Pienso que, frente a la crisis de la literatura, en particular, y de las Humanidades en general, quizás un ejercicio práctico pendiente sea recuperar a los clásicos para cuestionar los cánones y las barreras que tan firmemente hemos trazado. Pienso en que la Poética nos ofrece una oportunidad para hacerlo, nos brinda la posibilidad de poner en práctica una verdadera interdisciplinariedad. Schaeffer acuña una metáfora ecológica y demográfica de las disciplinas y las presenta como si fueran tribus con territorios propios, en la que "cada una cultiva su jardín, desarrolla su idiolecto y se interesa esencialmente en su autorreproducción" ([2011] 2013: 32). Esta práctica ha generado dispersión de investigaciones y tendencia al intercambio endogámico. Las 
lecturas "literaria" y "filosófica" de la Poética son un claro ejemplo de ello. Quizás solo se trate de cruzar los cercos de nuestros jardines, de naturalizar nuestra concepción de arte, de estetizar nuestra concepción de la naturaleza, para volver a pensarnos sin fronteras ni abismos. ${ }^{21}$

\section{BIBLIOGRAFÍA}

Andersen, Ø. y Haarberg, J. (2003), Making Sense of Aristotle: Essays in Poetics (London: Duckworth)

Barnes, J. [1982] (1999), Aristóteles, trad. de M. Sansigre Vidal (Madrid: Cátedra).

Birulés, F. (1989), "Introducción”, en A. Danto, Historia y narración: Ensayos de filosofía analítica de la historia (Barcelona: Paidós, 9-27).

Bobes, C., Baamonde, G., Cueto, M., Frechilla, E., y Marful, I. (1995), Historia de la teoría literaria I: La antigüedad grecolatina (Madrid: Gredos).

Boeri, M. (1993), Aristóteles: Física I-II, traducción, introducción y comentario (Buenos Aires: Biblos).

Boulay, B. (2016), "Les lunettes du philosophe", Littérature, 182(2): 78-88.: URL = $<$ https://www.revues.armand-colin.com/lettres-langues/litterature/litterature-ndeg-182-22016/lunettes-du-philosophe>

Brun, J. [1961] (1970), Aristóteles y el Liceo, trad. de A. Maljuri (Buenos Aires: Eudeba).

Candel Sanmartín, M. (1982), Aristóteles: Tratados de Lógica (Órganon) I: Categorías, Tópicos, Sobre las refutaciones sofistas, introducciones, traducciones y notas (Madrid: Gredos).

Candel Sanmartín, M. (1995), Aristóteles: Tratados de Lógica (Órganon) II: Sobre la interpretación, Analíticos Primeros, Analíticos Segundos, introducciones, traducciones y notas (Madrid: Gredos).

Castillo Merlo, M. (2014), "Más allá de las fronteras del arte: el rol del aprendizaje mimético en la deliberación”, Discusiones Filosóficas, 25: 185-203. URL $=<$ https:// revistasojs.ucaldas.edu.co/index.php/discusionesfilosoficas/article/view/778>

Castillo Merlo, M. (2015) “Mímesis y phrónesis: la función política de la tragedia en

${ }^{21}$ Este trabajo se inscribe en el marco de las discusiones que desarrollamos sobre la obra de J.-M. Schaeffer en el proyecto de investigación "La experiencia estética más allá del arte: entre afectividad y moralidad” (04-H179, UNCO 2018-2021). Una versión preliminar fue expuesta en el marco del Simposio La noción de phýsis en Platón y Aristóteles y sus proyecciones en filósofos posteriores (AFRA, Mar del Plata, 2019). Agradezco a la Dra. Di Camillo y a mis compañeros/as de proyecto y de Simposio los comentarios y sugerencias realizadas. A la Dra. Seggiaro, además, su paciencia infinita. El aislamiento por la pandemia, la actividad académica y la maternidad no siempre logran conjugarse de la manera en que una quisiera. 
Aristóteles", Anacronismo e Irrupción. Revista de Teoría y Filosofía Política Clásica y Moderna, 5(8): 117-137. URL $=<$ https://publicaciones.sociales.uba.ar/index. $\mathrm{php} /$ anacronismo/article/view/1091/0>

Castillo Merlo, M. (2016), "Mímesis y máthesis: acerca de sus conexiones en la Poética de Aristóteles”, Diánoia, 61(77): 53-81. DOI: 10.21898/dia.v61i77.1475

Castillo Merlo, M. (2020a), "Entre tragedia y política: mímesis, emociones y entendimiento en Aristóteles”, en V. Suñol y L. R. Miranda (eds.), La educación en la filosofía antigua: Ética, retórica y arte en la formación el ciudadano (Buenos Aires: Miño y Dávila, 99-118).

Castillo Merlo, M. (2020b), "El rol de la comprensión en el aprendizaje mimético: entre Poética y Política”, en V. Suñol y M. Berrón (comps.), Educación, arte y política en la filosofía antigua. Actas del IV Simposio Nacional de la AAFA (Santa Fe: Asociación Argentina de Filosofia Antigua, 158-166).

Danto, A. [1965] (1989) Historia y narración: Ensayos de filosofía analítica de la historia, trad. de E. Bustos (Barcelona: Paidós).

Destrée, P. (2003), "Présentation", Les Études philosophiques, 67(4): 433-435. DOI: 10.3917/leph.034.0433

De Montmollin, D. (1951), La Poétique d'Aristote, texte primitif et additions ultérieures (Neuchâtel: Meiseller).

Dolĕzel, L. [1990] (1997), Historia breve de la poética: Teoría de la literatura y literatura comparada, traducción de L. Alburquerque (Madrid: Síntesis).

Donini, P. (1997), “Poetica e Retorica”, en E. Berti (ed.), Guida ad filosofi Aristotele (Bari: Laterza, 327-363).

Ducrot, O. y Todorov, T. [1972] (1991), Diccionario enciclopédico de las ciencias del lenguaje (México: Siglo XXI).

Ducrot, O. y Schaeffer, J.-M. [1995] (1998), Nuevo diccionario enciclopédico de las ciencias del lenguaje (Madrid: Arrecife).

Düring, I. [1966] (2005), Aristóteles: Exposición e interpretación de su pensamiento, traducción de B. Navarro (México: Instituto de Investigaciones Filosóficas-UNAM).

Else, G. (1957), Aristotle's Poetics: The Argument (Cambridge: Harvard University Press).

Foucault, M. [1969] (2006), La arqueología del saber, traducción de A. Garzón del Camino (Buenos Aires: Siglo XXI).

García Yebra, V. (1970), Aristóteles. Metafísica, edición trilingüe (Madrid: Gredos).

García Yebra, V. [1974] (1985), Aristóteles. Poética, edición trilingüe (Madrid: Gredos).

Garrido Gallardo, A. (1988), Teoría de los géneros literarios (Madrid: Arco Libros).

Halliwell, S. (1987), The Poetics of Aristotle, translation and commentary (London: Duckworth).

Halliwell, S. (1998), Aristotle's Poetics (Chicago: The University of Chicago Press).

Halliwell, S. (2011), Between Ecstasy and Truth: Interpretations of Greek Poetics from Homer to Longinus (Oxford: Oxford University Press).

Hardy, J. (1952), Aristote. Poétique, texte établi et traduit (Paris: Les Belles Lettres). 
Jaeger, W. [1946] (2001), Paideia: Los ideales de la cultura griega, traducción de J. Xiral (México: Fondo de Cultura Económica).

Jiménez Sánchez-Escariche, E. y Miguel, A. A. (2000), Aristóteles. Partes de los animales. Marcha de los animales. Movimiento de los animales, traducción, introducción y notas (Madrid: Gredos).

Kaufmann, W. [1968] (1978), Tragedia y filosofía, traducción de S. Oliva (Barcelona: Seix Barral).

Lacoue-Labarthe, P. (2010), La imitación de los modernos (Tipografías 2), traducción y epílogo de C. Durán (Buenos Aires: La Cebra).

Laudan, L. (1987), "Progress or Rationality?:The Prospects for Normative Naturalism", American Philosophical Quarterly, 24: 19-31. URL = <http://www.jstor.org/ stable/20014171>

Lesky, A. [1963] (1989), Historia de la literatura griega, traducción de J. M. Diaz Regañon y B. Romero (Madrid: Gredos).

Leunissen, M. (2017), From Natural Character to Moral Virtue in Aristotle (New York: Oxford University Press).

Lloyd, G. E. R. [1968] (2008) Aristóteles: Desarrollo y estructura de su pensamiento, traducción de M. L. Femenías (Buenos Aires: Prometeo).

Long, A. A. (1990), “Aristóteles”, en P. E. Easterling y M. W. Knox (eds.), Historia de la literatura clásica: Literatura griega (Madrid: Gredos, 571-586).

Lucas, D. W. (1968), Aristotle. Poetics, introduction, commentary and appendixes (Oxford: Clarendon Press).

Marías, J. y Araujo, M. (1989), Aristóteles. Política, edición bilingüe y traducción (Madrid: Centro de Estudios Constitucionales).

Moreau, J. [1962] (1972), Aristóteles y su escuela, traducción de M. Ayerra (Buenos Aires: Eudeba).

Mouza, L. (2003), "Se connaitre soi-même: tragédie, bonheur et contingence", Les études philosophiques, 67(4): 483-498.

Pallí Bonet, J. (1992), Aristóteles. Investigación sobre los animales, traducción y notas, (Madrid: Gredos).

Pallí Bonet, J. (2000), Aristóteles. Ética Nicomáquea. Ética Eudemia, traducción y notas (Madrid: Gredos).

Petit, A. (1997), “'L'art imite la nature': les fins de l'art et les fins de la nature”, en P. M. Morel (ed.), Aristote et la notion de nature: Enjeux épistémologiques et pratiques (Bordeaux: Presses Universitaires de Bordeaux, 35-43).

Racionero, Q. (1994), Aristóteles. Retórica, introducción, traducción y notas (Madrid: Gredos).

Ricœur, P. [1985] (1995), Tiempo y Narración I: Configuración del tiempo en el relato histórico, traducción de A. Neira (México: Siglo XXI).

Rodríguez Adrados, F. (1972), Fiesta, comedia y tragedia: Sobre los orígenes del teatro (Barcelona: Planeta). 
Ross, W. D. [1923] (1995), Aristóteles, traducción de D. Pró (Buenos Aires: Sudamericana).

Sánchez, E. (1994), Aristóteles. Reproducción de los animales, introducción, traducción y notas (Madrid: Gredos).

Schaeffer, J.-M. [1989] (2006), ¿Qué es un género literario?, traducción de J. Bravo Castillo y N. Campos Plaza (Madrid:Akal).

Schaeffer, J.-M. [2011] (2013), Pequeña ecología de los estudios literarios: ¿Por qué y cómo estudiar la literatura?, traducción de L. Fólica (Buenos Aires: Fondo de Cultura Económica).

Suñol,V. (2012), Más allá del arte: Mímesis en Aristóteles (La Plata: EDULP).

Vallejo Campos, A. (2005), Aristóteles. Fragmentos, introducción, traducción y notas (Madrid: Gredos).

Veloso, C. W. (2004), Aristóteles mimético (Sâo Paulo: Discurso).

Willems, G. (1981), Das konzept der literarischen Gattung (Tubinga: Max Niemeyer).

Recibido: 13-05-2020; aceptado: 16-03-2021 